\title{
Determination for structure and spectral characteristics of tabular beryl
}

\section{crystal}

\author{
HE Tao ${ }^{1}$, YIN Qiong ${ }^{2, *}$
}

1.Department of Biological and Environmental Engineering, Tianjin Vocational Institute, Tianjin, China

2.School of Mining Technology, Kunming Metallurgy College, Kunming, Yunnan, China

*. Correspondence author

Key words: Beryl, optical characteristics, inclusion, crystal, structure determination

\begin{abstract}
Beryl in nature is columnar crystal generally; Beryl of clintheriform is quite rare. Different thermal luminescent effect occurs due to difference in geological and geochemical conditions for mineralization, and crystal lattice defects, impurity element content, radiation dose received from outside, thermal history and other items of beryl. There is negative crystal inclusion of ditrigonal scalenohedron in crystal, from an analysis of mineral deposit characteristics, inclusion, spectroscopic characteristics, optimization processing, artificial synthesis and other aspects of beryl. It can be concluded from the said analysis: Beryl crystal of clintheriform is huge and of perfect shape, high diaphaneity and high gemological value. And its peculiar paragenetic combination is of extremely high ornamental value.
\end{abstract}

\section{Causes of beryl}

Beryl is beryllium-aluminosilicate mineral. Colors of its varieties are different, pale blue (called as aquamarine), dark green (called as emerald), golden yellow (called as golden beryl), pink (called as morganite) and etc. The pale bluish green one is the most common. Beryl is of hexagonal cylindrical crystal generally and of various colors in most cases. Beryl is Be3Al2(SiO3)6, where Be and $\mathrm{Al}$ may be replaced by different microelement to make various colors appear in it.

\section{Origin and inclusion of beryl}

According to research, origins of emerald in the world are mainly located in Columbia and Russia, which occupy more than $90 \%$ of world output. The next places are South Africa (Azania), Indian, Brazil, Tanzania, Zambia and etc. Emerald from Columbia is recognized to be the best one in the world. Its color is pure green; minority is yellowish green or bluish green. It is automorphic, 1 - $2 \mathrm{~cm}$ in diameter, $3-5 \mathrm{~cm}$ in length and 10ct to tens of ct in weight. Huge emerald can be thousands of ct in weight. Emerald from Columbia is of good quality and high output. Columbia outputs more than 2000ct of high-end emerald, 10 thousand to thousands of ct of middle and low-end one on a daily basis, which takes up $90 \%$ of annual output in the whole world. Emerald from Russia and South Africa is of good quality and a color slightly paler than that from Columbia with more defects inside. Products of Brazil and Indian are of poor quality and a much lower price.

Elements of fluid inclusion are complex. Fluid inclusion can be subdivided into seed crystal-containing one and seed crystal-free one. There are two types of seed crystal-containing 
inclusion: (1)seed crystal-gas-fluid three-phase inclusion, colorless and transparent branch mineral of perfectly round, irregular and other shapes, fluid components based on $\mathrm{CO} 2$ and $\mathrm{H} 2 \mathrm{O}$, including $\mathrm{CH} 4 、 \mathrm{Cl}-$ and $\mathrm{HS}$, gas components based on $\mathrm{CO} 2 、 \mathrm{H} 2 \mathrm{O} 、 \mathrm{CH} 4$ and $\mathrm{N} 2$; (2) seed crystal-gas-fluid-fluid four-phase inclusion, gas and fluid components based on $\mathrm{CO} 2$, including slight $\mathrm{CH} 4$ and HS, fluid $\mathrm{CO} 2$ containing slight HS, fluid water containing $\mathrm{CO} 2, \mathrm{CH} 4$ and $\mathrm{C} 2 \mathrm{H} 4$. Fluid-fusion inclusion is one form between solid inclusion and fluid inclusion. There are different types of inclusion in beryl from different mineral deposit type and different origins. For one or more types of inclusion, both formation temperature and pressure are different. Generally, temperature for forming solid inclusion is higher and for forming fluid inclusion lower. Existence of different types of inclusion reflects complexness and multi-phase of diagenesis and mineralization of beryl.

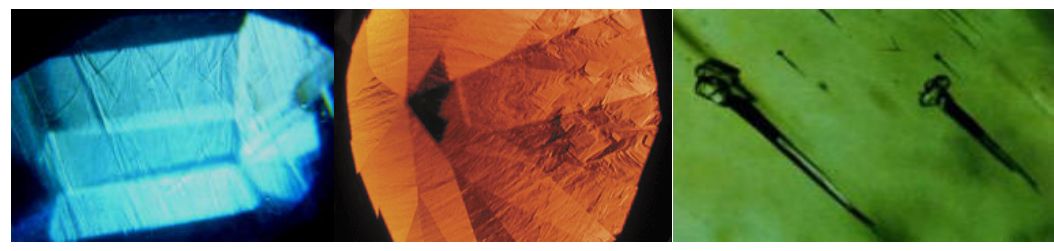

Figure 1 Texture and Inclusion of Beryl

Through study for inclusion in beryl, cause and origin of beryl can be judged so as to provide theoretical basis for finding more gemstone deposits in the future.

\section{Spectral signature of beryl}

Chemical formula of beryl is $\mathrm{Be}_{3} \mathrm{Al}_{2}\left(\mathrm{SiO}_{3}\right)_{6}$. Different gem species may contain microelements like chromium, ferrum, lithium and vanadium, which is the cause of coloring. Color: generally blue, yellow, black, red and colorless. Luster: vitreous luster. Diaphaneity: Diaphaneity-translucency-opacity. Refractive index: 1.56-1.59, depending on variety of gemstone. Birefringence: $0.004 \sim 0.009$, depending on variety of gemstone. Optical properties: uniaxial crystal, negative optical property. Chromatic dispersion: low. Pleochroism: obvious, depending on variety of gemstone.

Table 1 Pleochroism of Beryl

\begin{tabular}{|l|l|l|}
\hline Variety & Color & Pleochroism \\
\hline Emerald & Virid and green & Bluish green and yellow green \\
\hline Aquamarine & Ocean blue and sky blue & Green and colorless \\
\hline Morganite & Rose red & Pink and blue pink \\
\hline Golden beryl & Golden yellow & Varied \\
\hline Dun beryl & Dun & None \\
\hline
\end{tabular}

Absorption spectrum: Not typical, not obvious in aquamarine, fuzzy weak zone at 456nm of blue area, strong wide zone at $427 \mathrm{~nm}$ of purple area, occasionally one absorption zone at $537 \mathrm{~nm}$. Dissociation: Inadequate dissociation parallel to crystal ground. Fracture: shell-shaped. Hardness: 7.25 7.75. Tenacity: low in emerald and high in other beryl gemstone. Density: 2.65 2.9g/cm3, depending on variety of gemstone. 
Table2. Absorption spectrum Variety, Color, Pleochroism

\begin{tabular}{|l|l|l|}
\hline Variety & Color & Pleochroism \\
\hline Aquamarine & Sky blue & Fe, or Fe/Fe \\
\hline Goshenite & Colorless & Pure, free of elements for coloring causes \\
\hline Pink beryl & Pink & Cs Containing Mn or Cs \\
\hline Red beryl & Red & Coloring with Mn \\
\hline Golden beryl & Yellow-golden yellow & Coloring withFe \\
\hline Beryl & None & Fe+ Fe \\
\hline Maxixe beryl & Blue & Coloring with color center, unstable \\
\hline
\end{tabular}

Beryl is mainly produced from granite pegmatite and also seen in sandstone and mica schist; and it symbioses with tin and tungsten. Main minerals are located in Austria, Germany and Ireland in Europe, Madagascar in Africa, the Urals in Asia and northwest China. Beryl is the main raw mineral material for extracting beryllium and the one of beautiful color is precious gemstone, such as emerald and aquamarine.

1. Cleavage: Incomplete basal cleavage

2. Hardness: 7.25-7.75 fragile emerald

3. Relative density: $2.7-2.9$ change with the place of origin and variety

4. Luster: Vitreous luster

5. Transparency: Transparent to semitransparent

6. Refractive index: $1.56-1.59$ change with the variety

7. Birefringence: 0.004-0.009 change with the variety

8. Optical characteristic: Negative optical property of uniaxial crystal

9. Chromatic dispersion: Lower than 0.014

10. Special optical effect: Chatoyancy and starlight effect

11. Color: Green, blue, olivine, yellow, pink and none

12. Pleochroism: Different due to the color

The hexagonal system, $\mathrm{a} 0=0.9188 \mathrm{~nm}, \mathrm{c} 0=0.9189 \mathrm{~nm}$; $\mathrm{Z}=2$. Its basic structure is formed by the parallel arrangement of hexagonal ring axis $\perp$ c constituted by the [SiO4] tetrahedron, with upper and bottom rings reversing for 25 and being connected by $\mathrm{Al} 3$ and Be2; as the A1 coordination number is 6 and Be coordination number is 4, both of which are distributed outside of the ring, there is the wide channel at the axis // $\mathrm{c}$ in the center of the ring to contain the positive ions with long radius - $\mathrm{K}, \mathrm{Na}, \mathrm{Rb}, \mathrm{Cs}$ and water molecules. Because of its unique hexagonal loops or rings, traditionally, the beryl is put under the ring silicate, while its three-dimensional connectivity of tetrahedron framework makes it to be different from the real ring silicate (such as the tourmaline).

The hexagonal bipyramid crystal class D6h-6/mmm (L66L27PC). The crystal usually is in long columnar, while the crystal rich in alkali is in stumpy, or in shape of plate with development along with $\{0001\}$. Common monotype: The hexagonal prism $m\{10-10\}$, the pinacoid $c\{0001\}$, then is the hexagonal bipyramid $s\{11-21\}, \mathrm{p}\{10-11\}, \mathrm{o}\{11-22\}$ and the hexagonal prism a\{11-20\}, etc. There normally are the stripe of axis // c on the column surface, while the stripe on the column surface of alkali-free beryl is more obvious than that of alkaliferous beryl.

\section{Beryl determination}

Four standards of beryl identification: 1. Color: The onewith color of green with blue is good, and the one with color of green with gray has a worse quality. 2. Transparency: The limpid, bright, glittering and translucent ones are the good items, and the semitransparent ones are the normal 
items. Degree of purity: There normally are some inclusions inside of emerald, while the pure ones are the rare items of top grade. The emerald has a low price mainly due to its worse degree of purity. 3. Cutting: The standard cutting is called as emerald cut, which can completely and thoroughly reflex the gemstone luster. 4. Weight: Normally, the emerald crystal is not big. After cutting, the ones with excellent quality and weight more than 2 karats are rarely seen, while the ones with weight more than 5 karats even are the god-given treasure.

Identification methods of beryl: 1 Magnification observation: the needle shape inclusions which are parallel arrangement were in intermittent arrangement. It is often referred to as "rain-shape" inclusion. 2. Multicolor observation: it can be weak to obvious pleochroism and green to blue and colorless. 3. Refractive index measurement: RI 1.570-1.585 DR 0.005-0.006. 4. Relative density: 2.68-2.80, it reduces in 2.65 heavy liquid and increases in 2.89 heavy liquid. 5. Absorption spectrum: when Fe content is high, the blue-violet region $427 \mathrm{~nm}$ and $456 \mathrm{~nm}$ have two absorption narrow-bands. 6. Special optical effect: When the tubular inclusion is parallel and in dense arrangement, it may sometime have chatoyancy.

\section{Conclusion}

Synthetic emerald is made by hydrothermal method rather than Weiniuer method. Manufacture of synthetic gemstone by Weiniuer method has a limit, namely the method is only suitable for synthesis of gemstone whose content is oxide, such as corundum and spinel. As through Weiniuer method, in the process from droplet crystal to pear-shape crystal, only the oxide can be crystallized quickly. Emerald belongs to silicates, and therefore does not applicable to the Weiniuer method. Synthetic emerald by princess cut is actually the spinel synthetics, as we cannot observe its dichroism or inclusion which helps to produce the rholite. Process content of emerald through hydrothermal mainly means put the crystal seed into emerald solution, to make they slowly crystallize. The gemstone after crystallization shall be pure, which is not suitable with conditions of many inclusions of natural emerald. So, imitators may add some fluxing agent during manufacture process, to make artificial emerald produce natural cloud-type inclusion after crystallization. As the kinds of fluxing agent are different, shapes of inclusions may be different. Sometimes, interesting pattern may be formed. Natural gemstones similar to aquamarine are blue topaz and colored zircon. Artificial synthetic aquamarines are blue spinel and artificial glass. The best method to distinguish it from topaz and zircon is the density: topaz is $3.59 \mathrm{~g} / \mathrm{cm} 3$, and zircon is $4.69 \mathrm{~g} / \mathrm{cm} 3$. The density is obvious larger, and we may have feeling of heavy when we weighing it by hand. We can observe the facet edges at bottom through magnifying glass. Topaz and zircon may have double shadows and shadow of aquamarine is not clear. Zircon has high dispersion. Crystal shape: Topaz is rhombic prism shape and zircon is tetragonal prism shape. Although color of artificial glass and artificial blue spinel are similar to it, they are homogeneous body and have no dichroism. So we can distinguish them based on this. Factors for evaluation and procurement basis of aquamarine are color, transparency and weight. Good items shall be in dark color, flawless and heavy weight. Features of aquamarine are they are of sky blue and ocean blue, glass luster, less inclusion, pure and transparent, lower dichroism and in hexagonal prism shape. We shall avoid striking when we wear it.

\section{Acknowledgement}

Project supported by Yunnan Province Science and Technology Foundation for Youths (2013FD058). 


\section{Reference}

[1] Yan Liu, Jun Deng, Guanghai Shi, et al. Geochemical and morphological characteristics of coarse-grained tabular beryl from the Xuebaoding W-Sn-Be deposit, Sichuan Province, western China[J]. American Journal of Surgery, 2012, 124(1):3-4.

[2] Zhang L J, Qing-Feng R, Rao C. The Crystal Growth and Characteristics of Etched Figures on c\{0001 Face of Tabular Beryl Crystal from Pinwu,China[J]. Acta Mineralogica Sinica, 2012, 32(1):1-670.

[3] Qi L. CRYSTAL DEFECT AND GROWTH MECHANISM OF ALKALI RICH BERYL CRYSTAL FROM PINGWU,SICHUAN,CHIAN[J]. Geological Science \& Technology Information, 2001.

[4] Atencio D. Matioliite, the Mg-analog of burangaite, from Gentil mine, Mendes Pimentel, Minas Gerais, Brazil, and other occurrences : American Mineralogist[J]. American Mineralogist, 2006, 91(10):1932-1936.

[5] Yang, J., Wang, H., Lv, Z., Wei, W., Song, H., Erol-Kantarci, M., ... \& He, S. (2016). Multimedia recommendation and transmission system based on cloud platform. Future Generation Computer Systems. 